\title{
THE PERMUTATION TEST FOR TESTING THE STATISTICAL SIGNIFICANCE OF THE POWER SPECTRUM ESTIMATION IN DENDROCHRONOLOGICAL ANALYSIS
}

\author{
ANDRZEJ KRAWCZYK and MAREK KRAPIEC \\ Faculty of Geology, Geophysics and Environmental Protection, AGH - University of Science and Technology, \\ Al. Mickiewicza 30, 30-059 Cracow, Poland
}

Received 15 May 2010

Accepted 4 October 2010

\begin{abstract}
The study presents a proposal of application of the statistical permutation test, known from other applications, for searching for the symptoms of cyclicity, in particular related to solar activity, in the annual growth sequences of trees. The test consists in generation of random sequences of the increment widths observed and comparison of their periodograms with the periodogram of the sequence analysed. This allows for evaluation of the significance of the individual frequencies in the total variability. The model calculations carried out indicate that in the studies on cyclicity in dendrochronological sequences satisfactory results could be obtained in the analysis of sets of the individual sequences (but not the chronologies produced from them). It is important to generate sufficiently high numbers (1000 and more) of random sequences and to apply relatively low significance levels (at 0.05 , or even 0.01 ).
\end{abstract}

Keywords: tree-rings, cyclicity, permutation test, dendrochronological analysis.

\section{INTRODUCTION}

Trees growing in the moderate climate conditions develop annual growths, whose widths vary from one year to another. The highest impact on the annual growth is usually due to the climatic conditions, the temperature and rainfall in particular. They are in turn related, among others, to the activity of the Sun which demonstrates its characteristic cyclical nature.

The first studies on the identification of so-called eleven-year solar cycle in sequences of living trees from the south-western part of the USA were carried out by an American astronomer A.E. Douglass (1909) at the beginning of the twentieth century. More recent studies on the identification of the solar cyclicity in dendrochronological sequences, resumed with the application of computers and the appearance of possibilities of fast calculations, did not yield unequivocal results. La Marche and Fritts (1972), having analysed the sequences from Canada, USA and Mexico, did not find any significant relation-

Corresponding author: A. Krawczyk

e-mail: akraw@geolog.geol.agh.edu.pl ships between the growth of trees and the solar cyclical nature. On the other hand, Mori (1981), Murphy (1991), and Murphy and Veblen (1992) demonstrated that distinct eleven-year fluctuations appeared in individual sequences of annual growths of trees from various sites in Australia and Taiwan. Also for Central Europe, some authors pointed out the appearance of cycles of 11-16 years in the tree-ring sequences, which could have been related to changes in the activity of the Sun (Feliksik, 1990, Lipp et al., 1992, Schweingruber et al., 1990 and Shchemelevas, 1977). The eleven-year cyclicity was also investigated in the growth sequences of the subfossil and fossil trees (Ammons et al., 1983, Krawczyk and Krąpiec, 2003a, 2003b and Kurths et al., 1993).

Recently, in connection with global warming, the tree-ring data are more and more often used for reconstruction of climate and solar variability (Dutilleul and Till, 1992, Helama et al., 2009, Kasatkina et al., 2007, Lindholm et al., 2009, von Lürte, 1991 and Rigozo et al., 2007, 2008).

The studies mentioned above demonstrate, that the solar cyclicity is by no means reflected in the annual growth sequences of trees with a uniform, similar power. This may be due to such factors as the diversified habitat con- 
ditions, various climatic conditions (drier or more humid periods), and also the anthropopressure in the last decades.

There are several methods of searching for cyclicity in the annual growth sequences (such as wavelet analysis, singular spectrum analysis, maximum entropy method or multitaper method - for details see e.g. Ghil et al. 2002 or Zanzi et al. 2007), but the basic is Fourier spectral analysis, yielding the results in form of the frequency characteristics of the sequences analysed - periodogram and the spectral density function, i.e. the function of the power spectral density. They display the mode of the distribution of the total sequence variability into the individual frequencies. This, in turn, allows for a simple, intuitive interpretation; if a given annual growth sequence is considered as a sum of sinusoidal (or co-sinusoidal) components of various frequencies (i.e. different periods), the maximal values of the periodogram or the spectral density function will signalize the components of the highest impact on the overall shape of the sequence.

However, the periodograms of purely random sequences are not ideally equalized; they usually exhibit numerous local maxima. Therefore, it is of key importance to distinguish these random maxima and the maxima brought about by the cyclic components really present in the sequence. One can never be sure, of course, but it is possible to evaluate probability of the occurrence of a maximum which would not be random. This may be done with various statistical significance tests (see e.g. Brockwell and Davis, 1991 and Thompson, 1982).

Unfortunately, appropriate and effective usage of such tests in dendrochronological applications is by no means simple or easy. They are generally restricted with various assumptions as to the distribution pattern of the input data and/or the way of the spectrum estimation. Moreover, they are often asymptotic in character, which requires that the sequences analysed be of appropriate, suitable length. On the other hand, the annual growth sequences of trees are usually relatively short (except the dendrochronological standards, but it is another question), and the distribution patterns of the increment width often distinctly diverge from the Gaussian distribution pattern required. It should be also noted, that scientists dealing with dendrochronology are usually not enough fluent in the matter to perform advanced mathematical and statistical operations.

In such a situation the authors of this study propose a simple, non-parametrical test which could be used in every case, regardless of the length of the annual growth sequence analysed, and also regardless of the distribution pattern of the increment width.

\section{PERMUTATION TEST OF THE SPECTRUM SIGNIFICANCE}

The idea of the permutation tests, born in the 1930s (Fisher, 1935 and Pitman, 1937), has found numerous applications in various statistical procedures. In the last years such tests are being implemented increasingly widely, thanks to the common use of computers, which solved the problem of the time-consuming calculations.
The possibility of construction of a permutation test for evaluation of the spectrum significance, results from the fact that if any cyclic component were hidden in the analysed sequence of the annual growth width, random changes of the order of the sequence elements should eliminate it. So, by analysing a sufficiently high number of such random sequences, it would be possible to evaluate the probability that the spectrum observed for a real sequence were random. In other words - for every period (or frequency) taken into account it may be evaluated whether the spectrum value observed differs significantly from the value expected for a random sequence, devoid of cyclic components.

Let $\left\{x_{i}\right\}, i=1, \ldots, N$, be the analysed sequence of the widths of $N$ following annual growth rings, whereas $\left\{I_{k}\right\}$, $k=0, \ldots, M-$ the sequence of the spectrum evaluation, most often it is simply the periodogram. Let us now make a random permutation of the elements of the sequence $\left\{x_{i}\right\}$, and for the sequence obtained $\left\{z_{i}\right\}$ - evaluate the spectrum $\left\{J_{k}\right\}$; this operation will be repeated $Q$ times. As a result, for every frequency $k$ there will be obtained $Q$ evaluations of the spectrum $J_{k}$, which will allow for evaluating the probability of random obtaining of the really observed value $I_{k}$.

As it could be seen, from the technical point of view the realization of the test proposed should not present any difficulties, although it is a laborious and time-consuming task. Therefore, it should be done with the appropriate computer software (e.g. programs Excel and Statistica). A radical solution would be the implementation of user's own computer program, allowing for automatic and fast execution of all the necessary calculations.

In order to evaluate the practical usefulness of the permutation test, several questions should be considered.

1) The result of proposed test is a random variable, of which current realization depends on random permutations of the elements of the source sequence, generated in the course of the calculations. Hence, it may be intuitively expected that the permutation number (i.e. the value of the parameter $Q$, established by the user), would significantly affect the reliability of the result obtained, in particular, for the $Q$ value too low, the result would be, to a high degree, random. So, it appears the question of the optimal, or at least the minimal, value $Q$, which could guarantee the required stability of the test.

2) The zero hypothesis verified with the test discussed says that any value of the spectrum, any local maximum in particular, does not represent the cyclic component present in the source sequence. It is a compound hypothesis, encompassing $M$ simple hypotheses, considering every frequency taken into account (the spectrum value for the frequency $f_{0}=0$ may be identically equalized to zero, transforming the input sequence into the zero average value). So, the question should be asked about the real level of the test's significance, i.e. the probability at which the test would suggest the presence of the cyclic components in the case of purely random sequences.

3) It could be expected that the higher the amplitude of the cyclic components in relation to the random noise accompanying, the easier these cyclic components of 
the source sequences would be detected. So, it would be interesting to check how weak relationships would be visible (recognizable) for the test.

In order to answer these questions, at least in part, a short simulation study was carried out, whose results allow to formulate several practical indications.

\section{Test stability}

For checking how the results of the permutation test depend on the number of random permutations of the elements from the source sequence (i.e. the value of the parameter $Q$ ), several tens of annual growth sequences were analysed. These sequences were transformed into the index sequences, related to the 50-year spline trend (Cook and Peters, 1981), and the significance of the periodograms calculated for them was verified with the permutation test, assuming gradually increasing values of the parameter $Q$. In each case the test was carried out 100 times, which allowed comparing the results.

Two typical examples are presented in Tables $\mathbf{1}$ and 2. It could be seen, that the satisfactory stabilization of the test results appears, in general, at the value $Q=1000$, so this value could be accepted as the standard. Additionally, repetition of the test might be recommended and in cases of divergent results, the number of the random choices could be increased to e.g. 5000 (see e.g. PardoIgúzquiza and Rodriguez-Tovar, 2000).

\section{Significance level}

In order to analyse the real significance level of the permutation test, model sequences of the noise of uniform distribution and the noise of normal (Gaussian) distribution were generated. For such sequences the number of statistically significant values of the periodograms should correspond to the test significance level assumed. It means, that e.g. for 200-element input sequences, for which 100 periodogram values would be evaluated, one

Table 1. Results of the permutation tests for the sequence 2OPN5

\begin{tabular}{lrrrrrr}
\hline \multirow{2}{*}{ Frequency } & \multicolumn{6}{c}{$\begin{array}{c}\text { Number of tests which indicated a given frequency } \\
\text { as significant at the significance level } \boldsymbol{\alpha}=\mathbf{0 . 0 5}\end{array}$} \\
\cline { 2 - 7 } & $\mathbf{Q = 1 0 0}$ & $\mathbf{Q = 2 5 0}$ & $\mathbf{Q = 5 0 0}$ & $\mathbf{Q = 1 0 0 0}$ & $\mathbf{Q = 2 5 0 0}$ & $\mathbf{Q = 5 0 0 0}$ \\
\hline 0.0217 & 11 & 1 & 0 & 0 & 0 & 0 \\
0.0326 & 100 & 100 & 100 & 100 & 100 & 100 \\
0.0435 & 100 & 100 & 100 & 100 & 100 & 100 \\
0.0543 & 50 & 56 & 66 & 80 & 92 & 100 \\
0.0978 & 85 & 97 & 100 & 100 & 100 & 100 \\
0.1087 & 76 & 93 & 100 & 100 & 100 & 100 \\
\hline
\end{tabular}

Table 2. Results of the permutation tests for the sequence $2 R R 15$

\begin{tabular}{lrrrrrr}
\hline \multirow{2}{*}{ Frequency } & \multicolumn{6}{c}{$\begin{array}{c}\text { Number of tests which indicated a given frequency } \\
\text { as significant at the significance level } \boldsymbol{\alpha}=\mathbf{0 . 0 5}\end{array}$} \\
\cline { 2 - 7 } & $\mathbf{Q = 1 0 0}$ & $\mathbf{Q = 2 5 0}$ & $\mathbf{Q}=\mathbf{5 0 0}$ & $\mathbf{Q = 1 0 0 0}$ & $\mathbf{Q = 2 5 0 0}$ & $\mathbf{Q = 5 0 0 0}$ \\
\hline 0.0278 & 18 & 10 & 9 & 0 & 0 & 0 \\
0.0370 & 78 & 96 & 93 & 98 & 100 & 100 \\
0.0648 & 69 & 88 & 93 & 100 & 100 & 100 \\
0.0741 & 47 & 61 & 66 & 78 & 85 & 100 \\
0.0926 & 100 & 100 & 100 & 100 & 100 & 100 \\
0.1296 & 92 & 99 & 100 & 100 & 100 & 100 \\
\hline
\end{tabular}

should expect, in average, ten significant values at the level 0.1 , five significant values at the level 0.05 , and one significant value at the level 0.01 .

The calculations were made for 1000 models for uniform noise and 1000 models for Gaussian noise, which allowed for relatively accurate evaluation of the distribution pattern; the random variables being the numbers indicated by the test as the significant values of the periodograms. Fig. 1 demonstrates that such distribution patterns for the significance levels 0.1 and 0.05 are similar to the symmetrical binomial distribution pattern, whereas at the significance level 0.01 the patterns become, for obvious reasons, slightly positively asymmetrical. The modal values are as expected, which unequivocally points to the accuracy of the test, but the variability remains high; the cases in which the permutation test overrates or underrates the number of the values considered to be significant are relatively frequent. In particular, the probability values that the test would indicate too high a number of the significant frequencies amount to 0.387 (uniform noise) and 0.372 (Gaussian noise) for the significance level $0.1,0.379$ and 0.355 , respectively, for the significance level 0.05 , and 0.290 and 0.301 , respectively, for the significance level 0.01 . Hence, in practical use it would be undoubtedly better to use the significance levels lower than normally.

\section{Test sensibility}

The test sensibility was recognized through the analysis of its results for the models, in which, beside the random noise, the cyclical component - given in form of the sinusoid - is present as well. Similarly as in the previous experiment, the calculations were made for 1000 models using uniform noise and 1000 models using normal noise, with gradual changes of the sinusoid component's amplitude. This procedure was aimed at answering the question: How strong should the cyclical signal (sinusoid) be for the test to indicate the corresponding frequency as significant. In the ideal situation it should be the only significant frequency.

The calculations carried out indicated that such an optimal result of the test could be expected only at a relatively high amplitude of the sinusoid component. Fig. 2
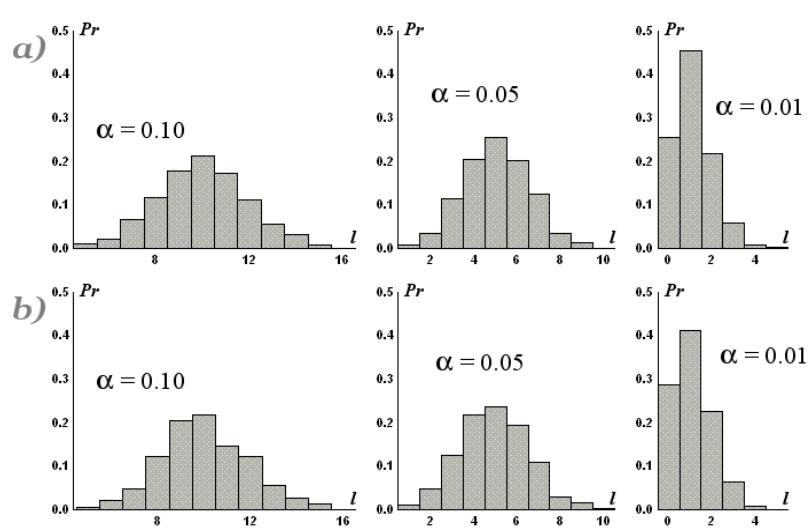

Fig. 1. Distribution patterns of the numbers of the periodogram significant values for the uniform noise (a) and the normal noise (b) at various significance levels. 
shows the probability values of obtaining such a distribution pattern for both kinds of the models. It is easy to notice that in the case of the models with the uniform noise, the probability of 0.9 (from the statistical point of view it is only a moderate value) would be reached only at the ratio of the sinusoid amplitude to the noise amplitude $\left(\mathrm{A}_{\mathrm{c}} / \mathrm{A}_{\mathrm{sz}}\right)$ close to 0.7 at the significance level of 0.01 , almost 1.0 at the level of 0.05 , and 1.2 at the level of 0.1 .
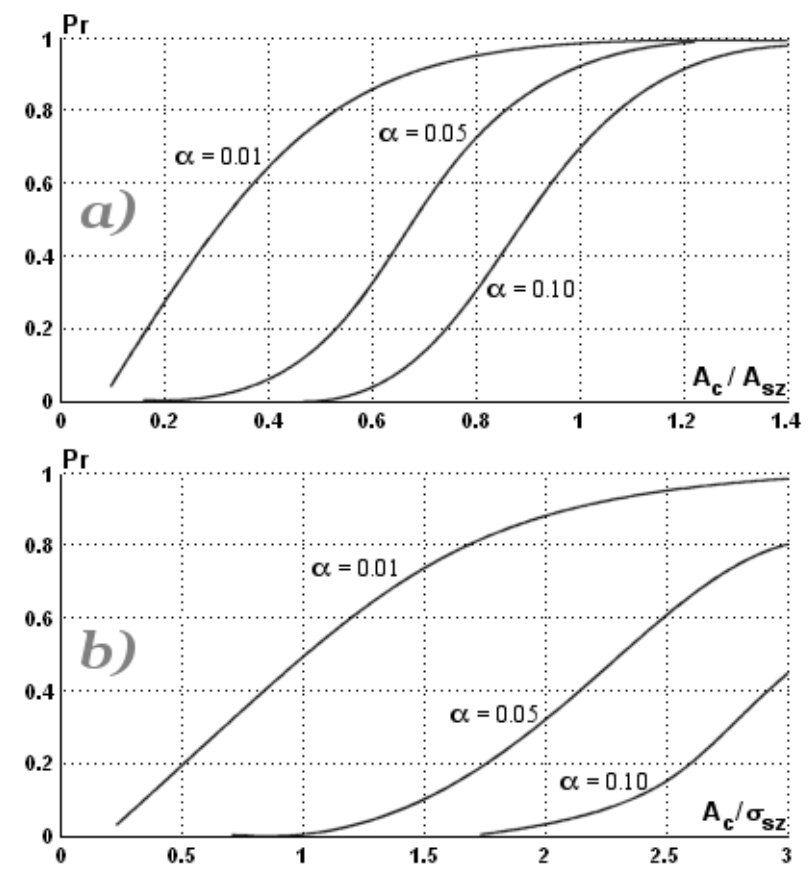

Fig. 2. Probability values of the indication of the cyclic component frequency as the only significant at the uniform noise (a) and the normal noise (b) for various significance levels. $A_{c}$ - amplitude of the cyclic component (sinusoid), $A_{s z}$ - amplitude of the uniform noise, $\sigma_{s z}-$ standard deviation of the normal noise.
In the case of the models with the normal noise, in order to achieve probability of 0.9 at the significance level of 0.01 the ratio of the sinusoid amplitude to the noise standard deviation $\left(\mathrm{A}_{\mathrm{c}} / \sigma_{\mathrm{sz}}\right)$ should be around 2 , and for lower significance levels this ratio should be still higher.

It does not mean, however, that the test proposed is useless. Figs. 3 and $\mathbf{4}$ present the results of the discussed experiment in another aspect; showing the probability with which a given frequency would be indicated by the test as significant, no matter whether other frequencies would be recognised by the test as equally significant. It may be seen that already at the values $\mathrm{A}_{\mathrm{c}} / \mathrm{A}_{\mathrm{sz}}=0.1$ for the random noise and $A_{c} / \sigma_{s z}=0.2$ for the normal noise this probability is significantly higher for the frequency of the cyclic component than for all other frequencies. At the increase of the sinusoid amplitude the discussed probability quickly rises as well, whereas the other probability values fall. The conclusion seems to be obvious; in order to search for the symptoms of the cyclicity in the dendrochronological sequences effectively, one should take into account not individual sequences, but the sets of them, representing populations of the trees from a given site. Only in such a case it would be possible to distinguish the random maxima of the periodograms from the maxima really indicating the external periodic factor, affecting all the analysed trees. Such maxima would appear, at least, at the majority of the sequences analysed.

\section{APPLICATION EXAMPLES}

In order to show the application of the proposed test in practice, three sets of the annual growth sequences of the Scots pine (Pinus sylvestris) were analysed. They all came from the sites in the vicinity of Cracow; 2NPLLIP and 2NPLGB from the Niepołomice Forest, and 2OPN from the Ojców National Park. Basic information on them is given in Table 3 and more exhaustive description - in the study of Zielski et al. (2001).
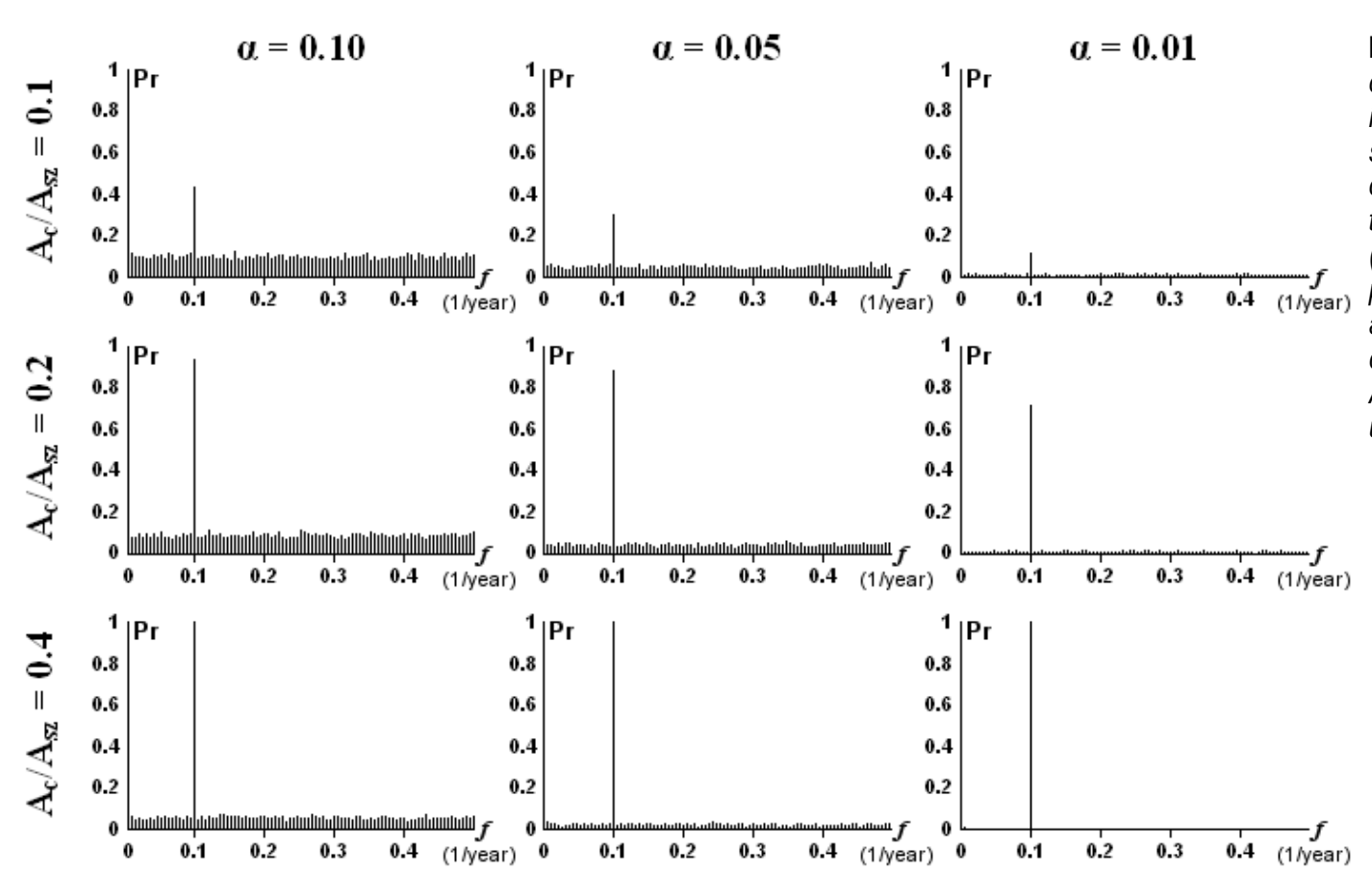

Fig. 3. Probability values of the indication of the individual frequencies as significant in the model of the uniform noise with the cyclic component (sinusoid) of a 10-year period added. $A_{c}$ amplitude of the cyclic component (sinusoid), $A_{s z}$ - amplitude of the uniform noise. 
The permutation tests, based on $Q=1000$ random choices, were made for all the individual sequences from all the analysed sites. Every test was repeated ten times, and only the values indicated as significant in all repetitions were considered as the significant values; the exemplary results (for the site 2NPLLIP and the significance level 0.05) are presented in Fig. 5a.

According to the scheme proposed above, it should be calculated how frequently (i.e. in how many individual sequences) a given frequency proved to be significant. At this step, however, a certain difficulty appears, related to the fact that the periodogram values evaluated are obtained for the discrete set of frequencies $f_{i}=i / 2 N, i=0 \ldots$, $N$, where $N$ is the length of the individual sequence examined. As the sequences from a given site are of various lengths (e.g. in the site 2NPLLIP the sequence length varies from 67 to 171), the results of the spectral analysis would not be directly comparable; the periodogram values evaluated would concern various frequency sets. This problem could be removed, however, through formal unification of all the sequences (addition of any number of zeros at the end of the sequence does not affect the spectral characteristics, but only changes the frequencies for which the periodogram is evaluated), but another solution seems to be simpler and more natural. It is easy to notice that the frequencies for which the periodogram is evaluated are distant each other about $\Delta f=f_{i+1}-f_{i}=$ $1 / 2 N$. So, every evaluation could be linked not to the exact frequency $f_{i}$, but to the range $f_{i} \pm \Delta f / 2$. Such a procedure seems to be justified, because it could guarantee indirect taking into account the resolutions of the individual periodograms, implied by the sequence lengths. The results of its application for the sequence from the site 2NPLLIP are presented in Fig. $\mathbf{5 b}$.

Now the calculations could be easily finished; their results for all three sites are presented in Fig. 6, in which the frequency scale was replaced by the period scale, cut to the most interesting range from 5 to 25 years. It could
Table 3. Characteristics of the exemplary sites

\begin{tabular}{ccccc}
\hline Site & $\begin{array}{c}\text { Laboratory } \\
\text { code }\end{array}$ & $\begin{array}{c}\text { Number } \\
\text { of se- } \\
\text { quences }\end{array}$ & $\begin{array}{c}\text { Sequence } \\
\text { length }\end{array}$ & Years \\
\hline $\begin{array}{c}\text { Niepołomice } \\
\text { Forest, } \\
\text { Lipówka } \\
\text { Reserve }\end{array}$ & 2NPLLIP & 12 & $67-171$ & $\begin{array}{c}1825- \\
1996\end{array}$ \\
\hline $\begin{array}{c}\text { Niepołomice } \\
\text { Forest, Gibiel } \\
\text { Reserve }\end{array}$ & 2NPLGB & 37 & $80-211$ & $1786-$ \\
\hline $\begin{array}{c}\text { Ojców Na- } \\
\text { tional Park }\end{array}$ & 2OPN & 11 & $85-95$ & $\begin{array}{c}1905- \\
1999\end{array}$ \\
\hline
\end{tabular}

be seen that the frequencies of the significant periodogram values are diversified, but all diagrams display a distinct maximum, corresponding to the periods of about eleven years. In the light of the model experiments described above, this could be interpreted as an indication of the basic, 11-year cycle of the solar activity.

\section{CONCLUSIONS}

The model experiments carried out indicated that the permutation test proposed could be an effective tool for searching the cyclicity symptoms (related to the solar activity, in particular) in the annual growth sequences of trees. The test should be performed with the appropriately high number (1000 or more) random sequences generated and at the low (0.05 at least) significance level. Moreover, it should not be carried out for the individual sequences, but for the groups (sets, populations) representing the same investigated site. This should enable to ignore random indications, appearing due to the random individual variability.
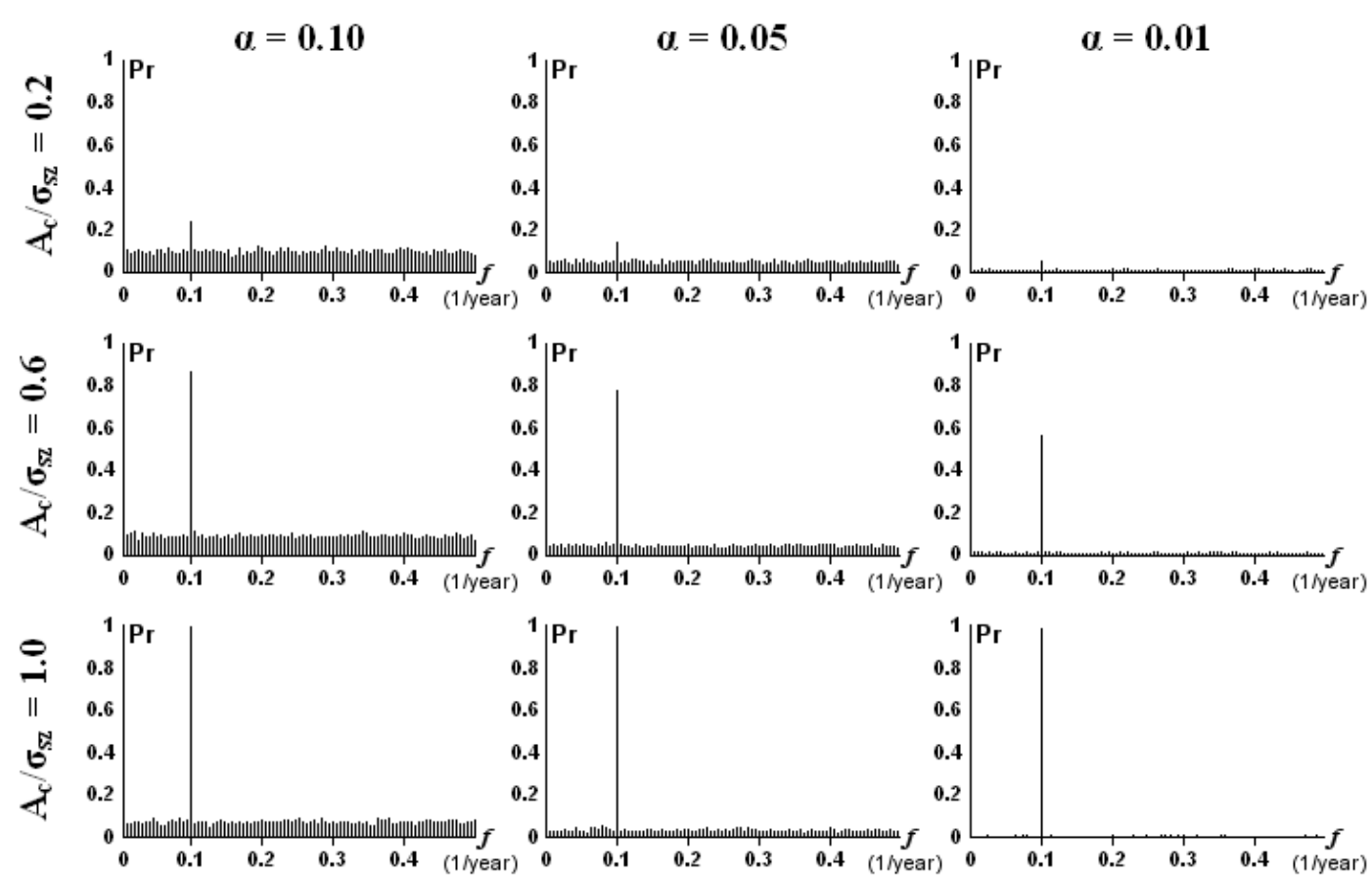

Fig. 4. Probability values of the indication of the individual frequencies as significant in the model with normal noise with the cyclic component (sinusoid) of a 10-year period added. $A_{c}-$ amplitude of the cyclic component (sinusoid), $\sigma_{s z}-$ standard deviation of the normal noise 


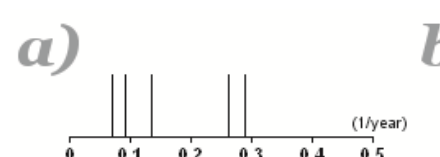

b)
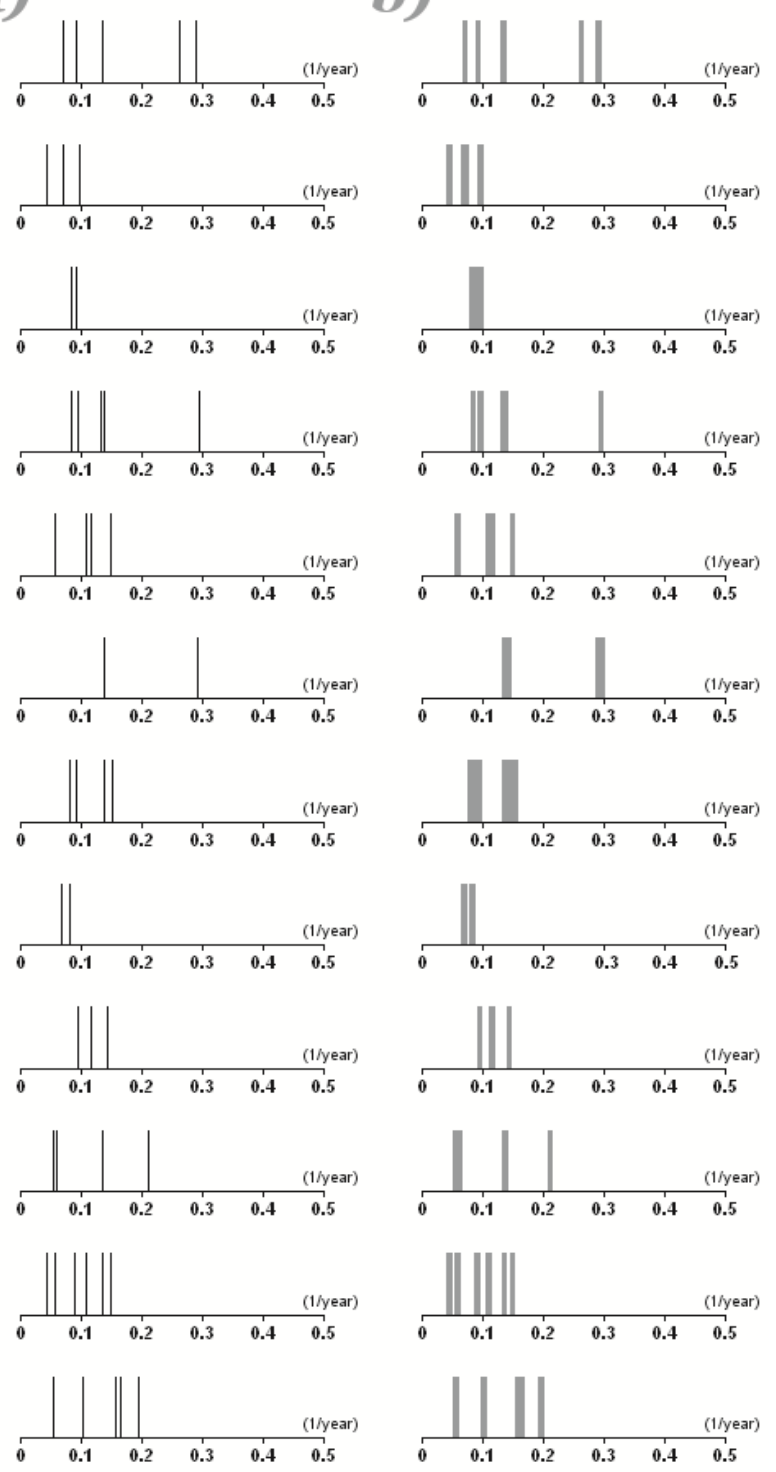

Fig. 5. Frequencies (a) and the corresponding ranges (b) of the periodogram values significant at the level 0.05 for the annual growth sequences of the trees from the site 2NPLLIP.

\section{REFERENCES}

Ammons R, Ammons A and Ammons RB, 1983. Solar activity-related quasi-cycles in Tertiary tree-ring records: evidence and methodological studies. In: McCormac BM, ed., Weather and Climate Responses to Solar Variations, Proceedings of the Second International Symposium on Solar-Terrestrial Influences on Weather and Climate, Boulder, CO, August 2-6, 1982. Colorado Associated University Press, Boulder: $535 \mathrm{p}$.

Brockwell PJ and Davis RA, 1991. Time Series: Theory and Methods. Springer, New York: 577pp.

Cook ER and Peters K, 1981. The smoothing spline: a new approach to standardizing forest interior tree-ring width series for dendroclimatic studies. Tree-Ring Bulletin 41: 45-53.

Douglass AE, 1909. Weather cycles in the growth of big trees. Monthly Weather Review 37: 225-237.

Dutilleul P and Till C, 1992. Evidence of periodicities related to climate and planetary behaviors in rings-width chronologies of Atlas cedar (Cedrus atlantica) in Marocco. Canadian Journal of Forest Research 22: 1469-1482, DOI 10.1139/x92-197.
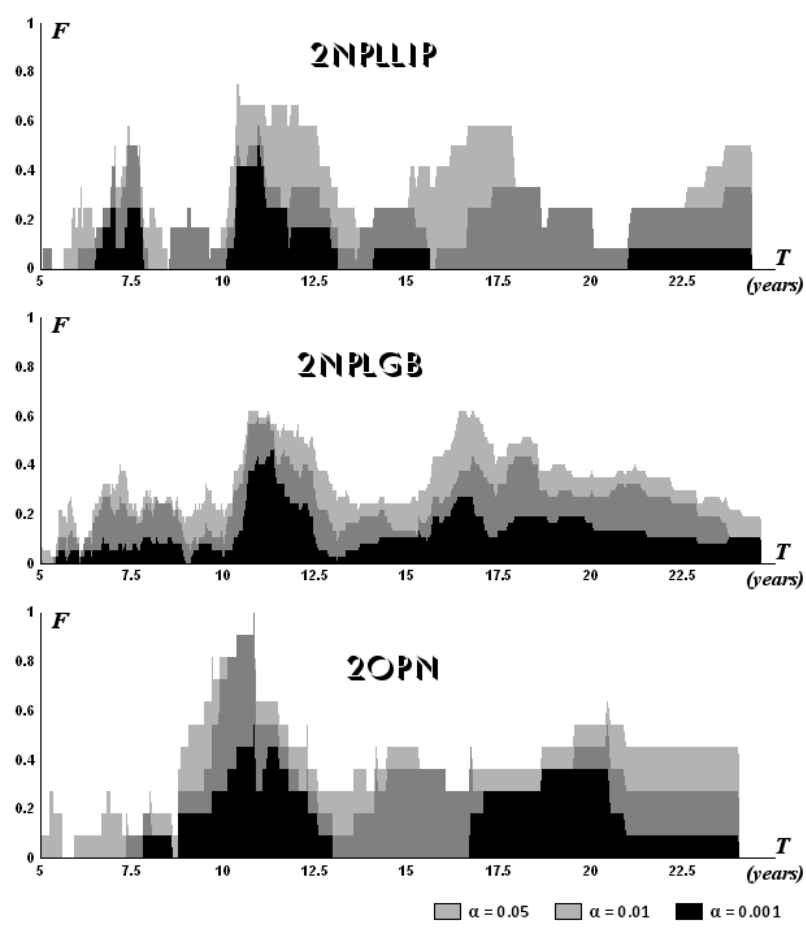

Fig. 6. Frequencies of the periods indicated as significant for the exemplary sites

Feliksik E, 1990. Badania dendroklimatyczne dotyczące jodły (Abies alba Mill.) występującej na obszarze Polski. (Dendroclimatological investigations of the common fir (Abies alba Mill.) from the territory of Poland). Zeszyty Naukowe AR Kraków 151: 106 pp (In Polish).

Fisher RA, 1935. The Design of Experiments. Oliver and Boyd, Edinburgh.

Ghil M, Allen MR, Dettinger MD, Ide K, Kondrashov D, Mann ME, Robertson AW, Saunders A, Tian Y, Varadi F and Yiou P, 2002. Advanced spectral methods for climatic time series. Reviews of Geophysics 40(1): 1-41, DOI 10.1029/2000RG000092.

Helama S, Makarenko NG, Karimova LM, Kruglun OA, Limonen M, Holopainen J, Meriläinen J and Eronen M, 2009. Dendroclimatic transfer functions revisited: Little Ice Age and Medieval Warm Period summer temperatures reconstructed using artificial neural networks and linear algoritms. Annales Geophysicae 27: 10971111.

Kasatkina EA, Shumilov OI and Krąpiec M, 2007. On periodicities in long term climatic variations near $68^{\circ} \mathrm{N}, 30^{\circ}$ E. Advances in Geosciences 13: 25-29, DOI 10.5194/adgeo-13-25-2007.

Krawczyk AJ and Krąpiec M, 2003a. Annual growth sequences and solar activity cycles (examples from subfossil oaks from Southern Poland). Bulletin of the Polish Academy of Sciences, Earth Sciences 51(1): 29-41.

Krawczyk AJ and Krąpiec M, 2003b. Schwabe solar cycle in tree-ring sequences from the last 4000 years (Southern Poland). Bulletin of the Polish Academy of Sciences, Earth Sciences 51(2): 91-97.

Kurths J, Spiering Ch, Müller-Stoll W and Striegler U, 1993. Search for solar periodicities in Miocene tree ring widths. Terra Nova 5(4): 359-363, DOI 10.1111/j.1365-3121.1993.tb00269.x.

La Marche V C and Fritts H C, 1972. Tree rings and sunspot number. Tree-Ring Bulletin 32: 19-33.

Lindholm M, Ogurtsov M, Aalto T, Jalkanen R and Salminen H, 2009. A summer temperature proxy from increment of Scots pine since 1561 at the northern timberline in Fennoscandia. The Holocene 19(8): 1131-1138, DOI 10.1177/0959683609345078.

Lipp J, Trimborn P and Becker B, 1992. Rhytmic $\delta$-D fluctuations in tree-ring latewood cellulose of spruce trees (Picea abies L.). Dendrochronologia 10: 9-22.

von Lürthe A, 1991. Dendroökologische Untersuchungen an Kiefern und Eichen in den stadtnahen Berliner Forsten. Landschaftsentwicklung und Umweltforschung. Schriftenreihe des Fachbereichs Landschaftsentwicklung der TU Berlin 77: 186 pp. 
Mori Y, 1981. Evidence of an 11-yr periodicity in tree-ring series from Formosa related to the sunspot cycle. International Journal of Climatology 1: 345-353, DOI 10.1002/joc.3370010407.

Murphy JO, 1991. The downturn in solar activity during solar cycles 5 and 6. Proceedings of the Astronomical Society of Australia 9(2): 330-331.

Murphy JO and Veblen TT, 1992. Proxy data from tree ring time series for the eleven year solar cycle. Proceedings of the Astronomical Society of Australia 10: 64-67.

Pardo-Igúzquiza E and Rodriguez-Tovar FJ, 2000. The permutation test as a non-parametric method for testing the statistical significance of power spectrum estimation in cyclostratigraphic research. Earth and Planetary Science Letters 181(1-2): 175-189, DOI 10.1016/S0012-821X(00)00191-6.

Pitman EJG, 1937. Significance Tests Which May Be Applied To Samples From Any Populations. Journal of the Royal Statistical Society - Supplement 4: 119-130.

Rigozo NR, Nordemann DJR, da Silva HE, Souza Echer MP and Echer E, 2007. Solar and climate signal records in tree ring width from Chile (AD 1587-1994). Planetary and Space Science 55(1-2):158164, DOI 10.1016/j.pss.2006.06.019.

Rigozo N R, Prestes A, Nordemann DJR, da Silva HE, Souza Echer MP and Echer E, 2008. Solar maximum epoch imprints in tree-rings width from Passo Fundo, Brazil (1741-2004). Journal of Atmospheric and Solar-Terrestial Physics 70(7): 1025-1033, DOI 10.1016/j.jastp.2008.02.002.

Shchemelevas YS, 1977. Climatic cycles and predictions in Lithuania., In: Fletcher JM and Linnard W, eds., Russian Papers on Dendrochronology and Dendroclimatology 1952, 1968, 1970, 1972. Research Laboratory for Archaeology and History of Art, Oxford University: 23-24.

Schweingruber FH, Aellen-Rumo K, Weber U and Wehrli U, 1990. Rhytmic growth fluctuations in forest trees of Central Europe and the Front Range in Colorado. Trees 4(2): 99-106, DOI 10.1007/BF00226072.

Thompson DJ, 1982. Spectrum Estimation and Harmonic Analysis. Proceedings of the IEEE 70(9): 1055-1096.

Zanzi A, Pelfini M, Muttoni G, Santilli M and Leonelli G, 2007. Spectral analysis on mountain pine tree-ring chronologies. Dendrochronologia 24(2-3): 145-154, DOI 10.1016/j.dendro.2006.10.002.

Zielski A, Krąpiec M, Wilczyński S and Szychowska-Krąpiec E, 2001. Chronologie przyrostów radialnych sosny zwyczajnej w Polsce (Chronologies of radial growths of Scots pine in Poland). Sylwan CXLV(5): 105-119 (In Polish). 